\title{
Epidemiological aspects and spatial distribution of human and canine visceral leishmaniasis in an endemic area in northeastern Brazil
}

\author{
Roseane Campos, ${ }^{1}$ Márcio Santos, ${ }^{1}$ Gabriel Tunon, ${ }^{1}$ Luana Cunha, ${ }^{1}$ Lucas Magalhães, ${ }^{1}$ \\ Juliana Moraes, ${ }^{1}$ Danielle Ramalho, ${ }^{1}$ Sanmy Lima, ${ }^{2}$ José Antônio Pacheco, ${ }^{2}$ \\ Michael Lipscomb, ${ }^{3}$ Amélia Ribeiro de Jesus, ${ }^{1,4,5}$ Roque Pacheco de Almeida ${ }^{1,4,5}$
}

${ }^{1}$ Laboratório de Biologia Molecular, Universidade Federal de Sergipe, Sergipe; ${ }^{2}$ Departamento de Geologia, Universidade Federal de Sergipe, Sergipe, Brazil; ${ }^{3}$ Department of Biology, Howard University, Washington, DC, USA; ${ }^{4}$ Departamento de Medicina, Universidade Federal de Sergipe, Sergipe; ${ }^{5}$ Instituto de Investigação em Imunologia, Instituto Nacional de Ciência e Tecnologia,

São Paulo, Brazil

\begin{abstract}
Visceral leishmaniasis (VL) is a systemic disease endemic in tropical countries and transmitted through sand flies. In particular, Canis familiaris (or domesticated dogs) are believed to be a major urban reservoir for the parasite causing the disease Leishmania. The average number of human VL cases was 58 per year in the state of Sergipe. The city of Aracaju, capital of Sergipe in Northeastern Brazil, had 159 cases of VL in humans. Correlatively, the percentage of serologically positive dogs for leishmaniasis increased from $4.73 \%$ in 2008 to $12.69 \%$ in 2014 .
\end{abstract}

Correspondence: Roque Pacheco de Almeida, Instituto de Investigação em Imunologia, Instituto de Investigação em Imunologia, Instituto Nacional de Ciência e Tecnologia, Avenida Doutor Enéas de Carvalho Aguiar 44, São Paulo, SP, Brazil.

E-mail: roquepachecoalmeida@gmail.com

Key words: Leishmaniasis; Epidemiological monitoring; Dog diseases; Spatial distribution; Brazil.

Acknowledgements: the authors thank the municipal health office and zoonoses control center in Aracaju-SE.

Funding: this work was supported by Coordenação de Aperfeiçoamento de Pessoal de Nível Superior (CAPES), Edital N 032/2010 (ARJ); CNPq). Grants: PROCAD/CASADINHO- n552721/2011-5 (RPA). The funders had no role in study design, data collection and analysis, decision to publish, or preparation of the manuscript.

Received for publication: 17 August 2016.

Revision received: 18 December 2016.

Accepted for publication: 2 January 2017.

(C) Copyright R. Campos et al., 2017

Licensee PAGEPress, Italy

Geospatial Health 2017; 12:503

doi:10.4081/gh.2017.503

This article is distributed under the terms of the Creative Commons Attribution Noncommercial License (CC BY-NC 4.0) which permits any noncommercial use, distribution, and reproduction in any medium, provided the original author(s) and source are credited.
Thus, these studies aimed to delineate the spatial distribution and epidemiological aspects of human and canine VL as mutually supportive for increased incidence. The number of human cases of VL and the frequency of canine positive serology for VL both increased between 2008 and 2014. Spatial distribution analyses mapped areas of the city with the highest concentration of human and canine VL cases. The neighbourhoods that showed the highest disease frequency were located on the outskirts of the city and in urbanised areas or subjected to development. Exponential increase in VL-positive dogs further suggests that the disease is expanding in urban areas, where it can serve as a reservoir for transmission of dogs to humans via the sand fly vector.

\section{Introduction}

Visceral leishmaniasis (VL) is a severe disease with high morbidity and lethality, if not treated. It occurs in 70 countries in tropical and subtropical areas, especially in Asia, Africa and South America (WHO, 2010). About $90 \%$ of VL cases occur in six countries: India, Bangladesh, Sudan, Southern Sudan, Ethiopia and Brazil (Werneck, 2014).

According to the data from the Brazilian Ministry of Health, the Northeast region of Brazil had the highest incidence of VL in 2013, with 1,745 new cases. In Aracaju, a city of in the north-eastern region of the country, 157 cases of VL were reported between 2009 to 2014, effectively making the area a major site for disease onset and transmission (Góes et al., 2012). One possible explanation is the adaptation of the vector Lutzomyia longipalpis to the peridomiciliary environment (Travi et al., 2002; Bhunia et al., 2010; Fischer et al., 2010; Faye et al., 2011). Although classified as a neglected disease, VL is re-emerging due to a clear process of changes in the epidemiological cycle. Studies have shown increased incidence in areas not traditionally endemic. Several epidemiological factors might explain the increased incidence of VL, which include, but not limited to: i) periurban areas of recent occupation and with an inadequate urbanisation; ii) constant migration processes; and iii) deforestation (Belo et al., 2013; Ribeiro et al., 2013; Werneck, 2014). For example, deforestation can reduce the food supply of the sand flies, thereby redirecting the vectors to target both humans and domestic dogs as an affordable alternative. Studies have clearly noted an increased percentage of serologically positive dogs for leishmaniasis from 4.73 in 
2008 to 12.69 in 2014 (Gramiccia, 2011).

Canis lupus familiaris, or domestic dogs, are considered an important parasite reservoir (Quinnell et al., 2003; Silva et al., 2005). In particular, this is because dogs are highly susceptible to the infection; furthermore, the proximity between humans and dogs furthers the transmission cycle propagated by the insect vector (Dantas-Torres et al., 2012, 2014). Epidemiological studies have shown that the number of domestic dog cases first rise, followed by a similar trend in human cases (Lopes et al., 2010), suggesting that the rise in the domesticated animals serve to increase transmission to humans (Gouvêa et al., 2007; Dantas-Torres et al., 2012). However, the majority of studies map human and dog cases separately and does not show a superposition in the geographic distribution of both dogs and human cases.

The development of digital mapping technologies (or geoprocessing) has opened new avenues for epidemiological investigations. In particular, using this technology, investigators are able to map and analyse the distribution of health-related outcomes in respect to epidemiological states. Spatial analysis studies further allow the identification of areas with the greatest potential for disease transmission, as we used to design risk-assessment maps. This approach can lead to optimising resources for disease monitoring and control (Almeida et al., 2011). Collectively, the aim of this study was to analyse the epidemiological aspects and evaluate the spatial distribution of dog and human cases of VL in the city of Aracaju to identify the potential correlation of Leishmania in dogs to that of increased incidence in humans. The exponential increase in VL-positive dogs and superposition of dogs and human cases in the same areas suggests that the disease is expanding in urban areas, with the transmission of dogs to humans via the sand fly vector.

\section{Materials and Methods}

\section{Area and study design}

An epidemiological time-series study was carried out, using secondary data obtained from SINAN (Information System of Notifiable Diseases) and Center for Zoonosis Control of the Aracaju city. Aracaju is the capital of the state of Sergipe, and is located in the eastern region of the State at the northeast of Brazil

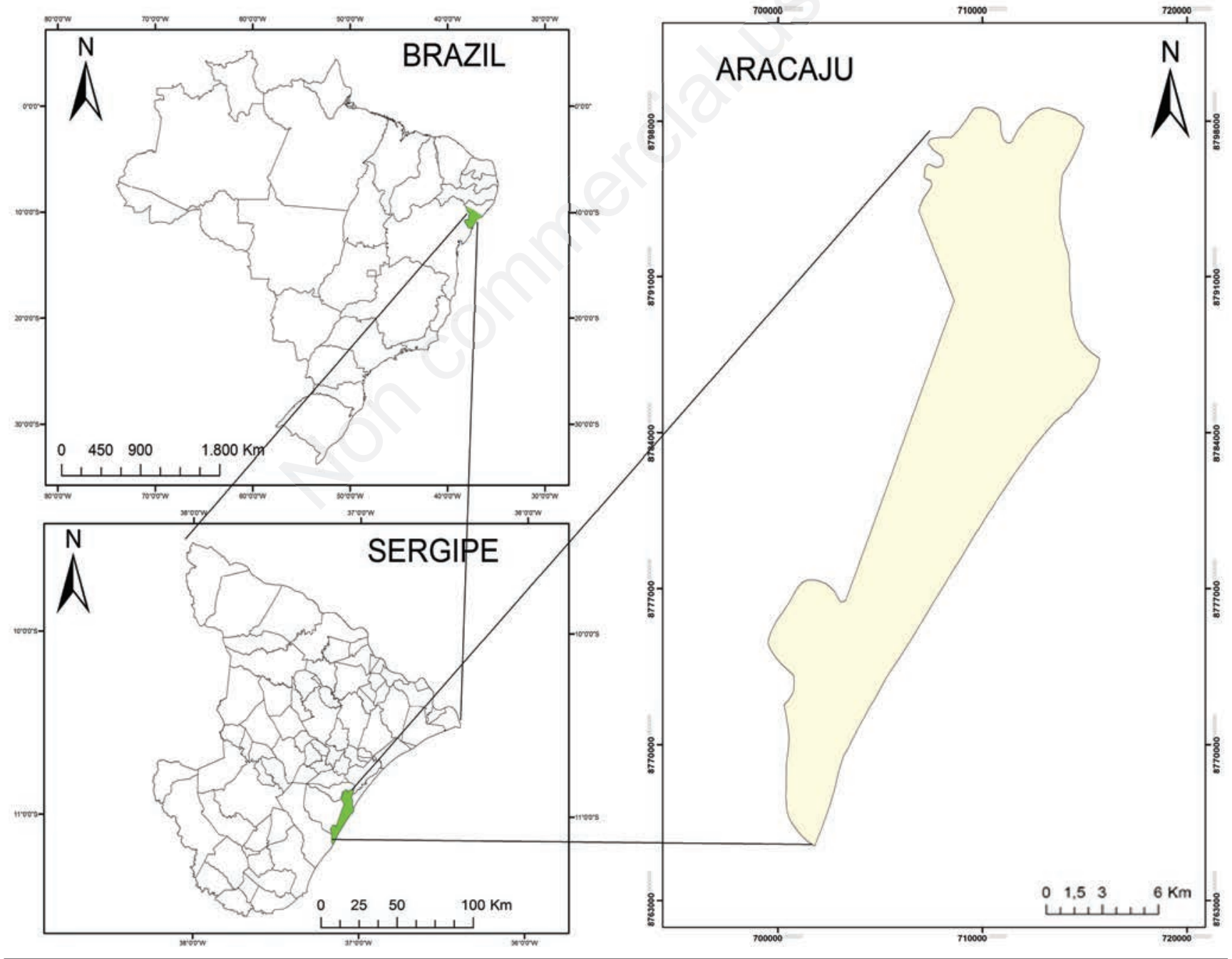

Figure 1. Map of Brazil showing the location of the state of Sergipe and the municipality of Aracaju within the state. 
$\left(10^{\circ} 54^{\prime} \mathrm{S}\right.$ and $\left.37^{\circ} 03^{\prime} \mathrm{W}\right)$. The city has an overall area of 181.8 $\mathrm{km}^{2}$ and an estimated population of 632,744 inhabitants in 2015, according to data from the Brazilian Institute of Geography and Statistics. The climate of Aracaju is hot humid and sub-humid. Its average temperature is $26^{\circ} \mathrm{C}$, annual rainfall of $1590 \mathrm{~mm}$, with rainy season from March to August. Aracaju is divided by 39 neighbourhoods (IBGE, 2015).

\section{Data source}

The human data were LV cases reported and confirmed, obtained from the National Notifiable Diseases Information System (SINAN), for the city of Aracaju. Data on canine VL were obtained from Aracaju Zoonosis Control Center. The positive dogs with Leishmania sp. infection was confirmed through the Rapid Test (DPP-Biomanguinhos, Rio de Janeiro, Brazil) and ELISA (Enzyme Linked Immuno Sorbent Assay, Biotek) for detection of antibodies to parasite antigens.

\section{Environmental variables}

A nested epidemiological descriptive study was also performed to evaluate epidemiological data associated with VL human cases. A questionnaire was applied to collect epidemiological data from the homes of families from 40 patients diagnosed with VL who were treated at the University Hospital of Aracaju from 2010 to 2012. The questionnaire included known risk factors for VL, such as presence of dog in the residence, nearby chicken coop and wood remains at home or around the houses. Delayed-type hypersensitivity tests (DTH) in response to soluble Leishmania antigen (SLA) were evaluated in the relatives of these VL cases.

\section{Statistical analysis of descriptive data}

A database was created in Microsoft Excel program (Version 2010). Descriptive data were analysed by calculating mean, median, frequencies, prevalence and incidence. To evaluate the strength of the association between the variables, the prevalence ratio (PR), and confidence intervals $(\mathrm{CI})$ were calculated by the chi-square test or Fisher's exact test. A $\mathrm{P}<0.05$ was considered for significance. All statistical analyses were performed in the Graph Pad Prism programme (version 6).

\section{Spatial distribution maps}

A database with the epidemiological serial data was built in Excel (version, 2010). The spatial distribution maps were performed by TerraView software (version 4.2.2). The cartographic grid of the Aracaju city with division by districts was provided by geoprocessing sector of Aracaju Municipal Health Department and QuickBird satellite.

\section{Ethical considerations}

This project was approved by the Ethical Committee of the Federal University of Sergipe CAAE-0123.0.107.000.11 and Ethical Committee Research with Animals number: 96/11.

\section{Results}

In the present study, we assessed and analysed temporal-spatial data comparing VL in humans and dogs in Aracaju (Figure 1). Average number of human VL cases was 58 per year in the state of Sergipe; Aracaju accounts for 18 of these cases. However, the spike in 2010 resulted in 83 VL cases in Sergipe, with 39 derived from Aracaju, and 2014 had 67 VL cases in Sergipe, with 32 cases from Aracaju (Figure 2A). Incidence coefficient (IC) showed that between 2008 and 2014, the rate of humans VL was higher in Aracaju than in Sergipe (Figure 2B). In 2008, the IC from Sergipe was 0.22 and from Aracaju was 0.34 ; in 2010 there was a significant increase in the IC of Sergipe (0.40) and Aracaju (0.68); and in 2014 the IC from Sergipe was 0.30 and Aracaju was 0.50 . Furthermore, the frequency of VL in dogs remained stable from 2008 to 2012 and increased significantly in 2013 and 2014 in Aracaju (Figure 2C).

Additionally, the results reveal that the incidence coefficient
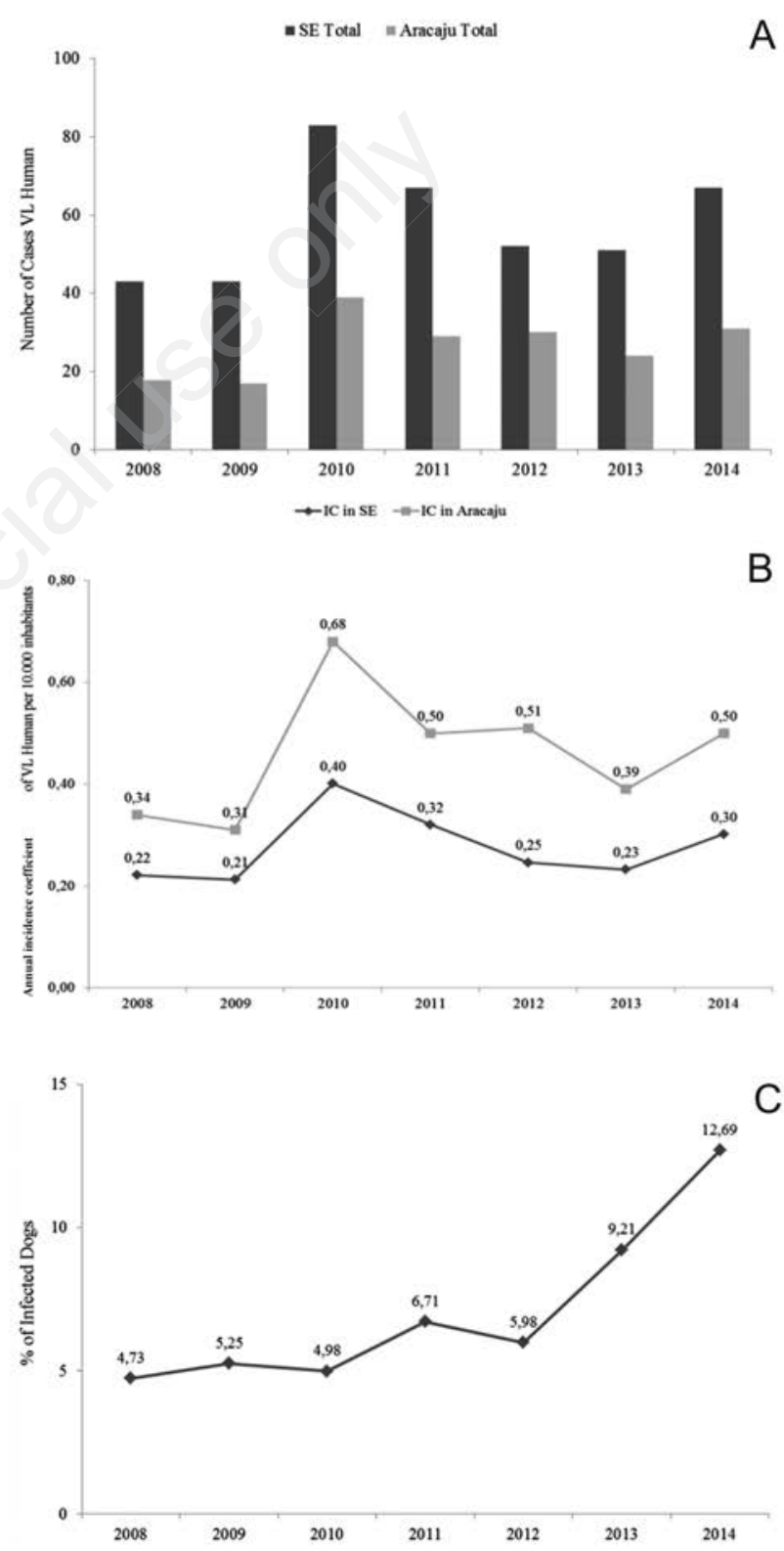

Figure 2. Total number of cases (A), annual incidence rates (B) of human visceral leishmaniasis cases and (C) percentage of dogs with positive serological tests for visceral leishmaniasis in the city of Aracaju and the state of Sergipe, Brazil, 2008-2014. 
was significantly higher in males than in females. In 2008, IC in males was 0.52 and in females it was 0.17 , in 2010 the IC in males was 1.02 and in females was 0.39 , and in 2014 the IC in males was 0.84 and females was 0.22 (Figure 3).

In all years analysed, the risk of VL was higher in males (Table 1), increasing significantly from the year 2008 [PR 2.99 (IC=1.068.38] $\mathrm{P}=0.028$ ] to 2012 [PR $3.78(\mathrm{IC}=1.62-8.81) ; \mathrm{P}=0.001]$. The differences in the frequency of $\mathrm{VL}$ in males and females, according to age distribution were not observed from 0 to 14 years. The sex difference in incidence was observed only in the age groups above 15 years $(\mathrm{P}=0.0021)$ (Figure 4$)$. The most significant difference was observed in the age group of 15 to 19 years, in which the proportion of males with VL was $10.9 \%$ vs females at $1.27 \%$. Interestingly, studies found frequencies of infected dogs were also higher in males than females (Figure 5).

Next, studies analysed the environmental factors that can lead to increased risk for Leishmania infection; the epidemiological factors include presence of dogs, chicken coops and woods. The frequency of DTH positive results and serological tests was $33.63 \%$. We observed that the majority of the homes $(80.49 \%)$ had at least one of these environmental factors considered at risk for Leishmania infection. $51.21 \%$ had dogs, $41.46 \%$ had chicken coops and $51.21 \%$ had wood remains in their homes. The combinations of dogs with wood remains were frequent $(31.7 \%)$, and chicken coops and dogs (17.07\%), and chicken coops and wood remains $(41.46 \%)$. All three variables were observed in $34.14 \%$ of the homes.

The analysis of the spatial distribution of canine and human VL total cases in the neighbourhoods of Aracaju from 2008 to 2014 (Figure 6) shows the existence of areas with a higher risk of transmission of leishmaniasis, with dogs and human VL cases mapped to the same neighbourhoods. The strong red colour shows a greater number of cases. The northern Aracaju and expansion zone have higher numbers of human and dog cases of VL.

In 2014, we observed that human VL cases were clustered in the north region of Aracaju. A satellite image was used to examine whether the districts in this region were conducive to the spread of the insect vector-borne disease. As observed in the satellite image, the areas with the highest number of VL cases occurred near places with high density of vegetation, rivers and canals, as well as home with lots of vegetation and debris (Figure 7). The districts most affected by the disease are the poorest areas of the city. Collectively, these results reveal that understanding the dynamics of transmission of this disease, as well as the identification of risk areas for infection is essential to direct actions of epidemiological surveillance programs of the municipality.

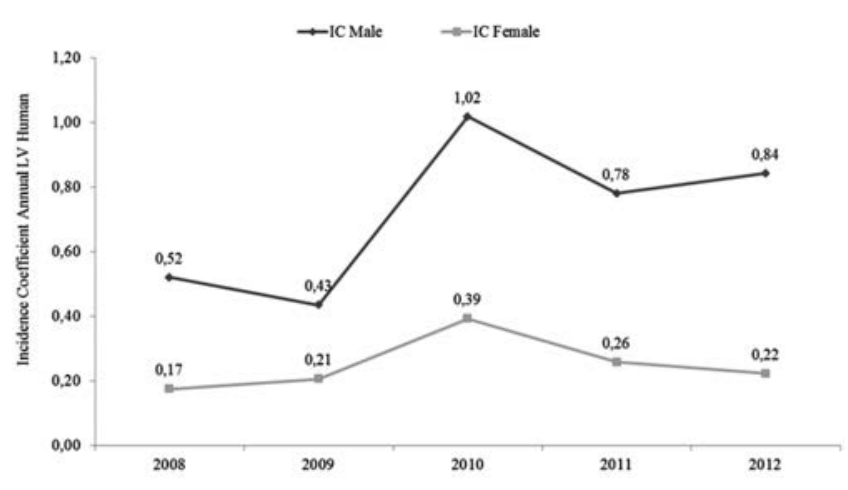

Figure 3. Annual incidence coefficient (IC) of human visceral leishmaniasis according to sex in Aracaju, Brazil, 2008-2012.

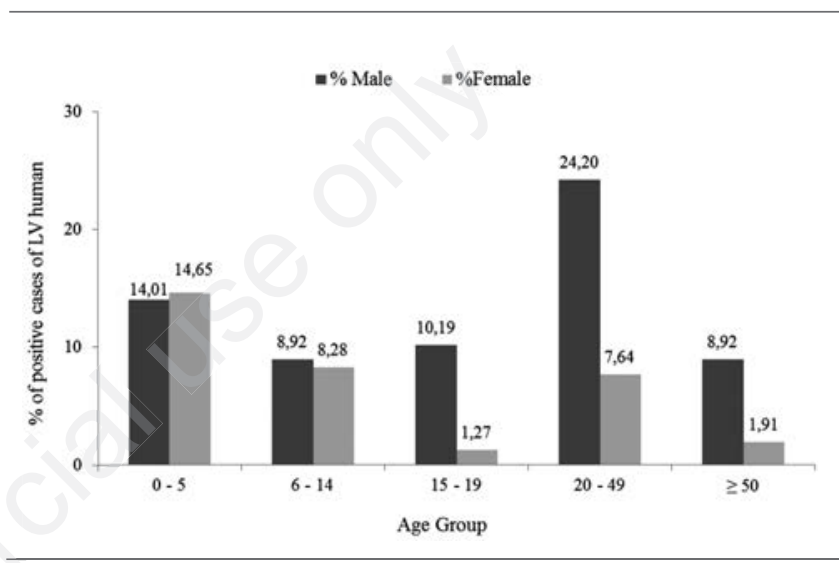

Figure 4. Frequency distribution of positive cases of human visceral leishmaniasis by sex, according to age group. Average data from 2008 to 2013, Aracaju, Brazil (P=0.0021).

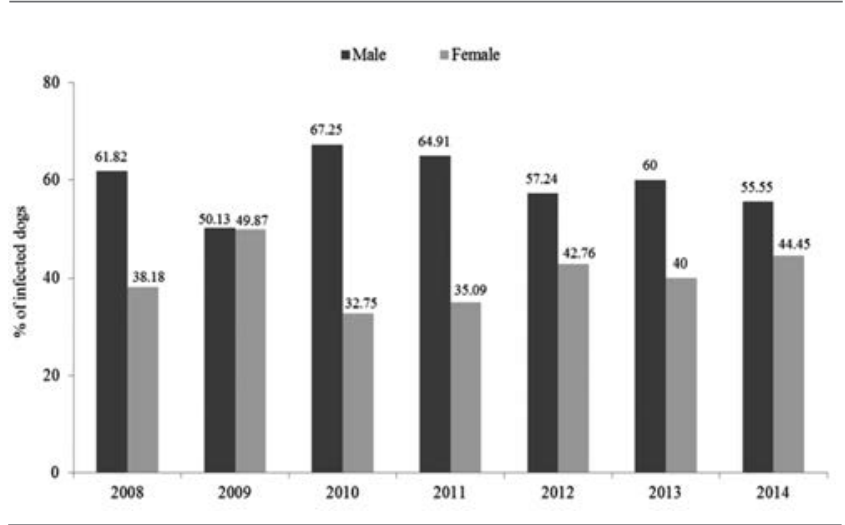

Figure 5. Frequency distribution of positive dogs for visceral leishmaniasis according to sex in Aracaju, Brazil, 2008-2014.

Table 1. Distribution of the percentage of positive human visceral leishmaniasis cases according to sex in Aracaju, Brazil, $2008-2012$.

\begin{tabular}{|c|c|c|c|c|c|}
\hline Year & Male & Female & PR & CI & P* \\
\hline 2008 & 72.2 & 27.8 & 2.99 & $1.06-8.38$ & 0.028 \\
\hline 2009 & 64.7 & 35.3 & 2.11 & $0.78-5.70$ & 0.21 \\
\hline 2010 & 69.2 & 30.8 & 2.59 & $1.31-5.11$ & 0.007 \\
\hline 2011 & 72.4 & 27.6 & 3.02 & $1.33-6.82$ & 0.009 \\
\hline 2012 & 76.7 & 23.3 & 3.78 & $1.62-8.81$ & 0.001 \\
\hline
\end{tabular}

$\mathrm{PR}$, prevalence ratio; CI, confidence interval testing the association strength of male gender with visceral leishmaniasis. *Chi square test. 

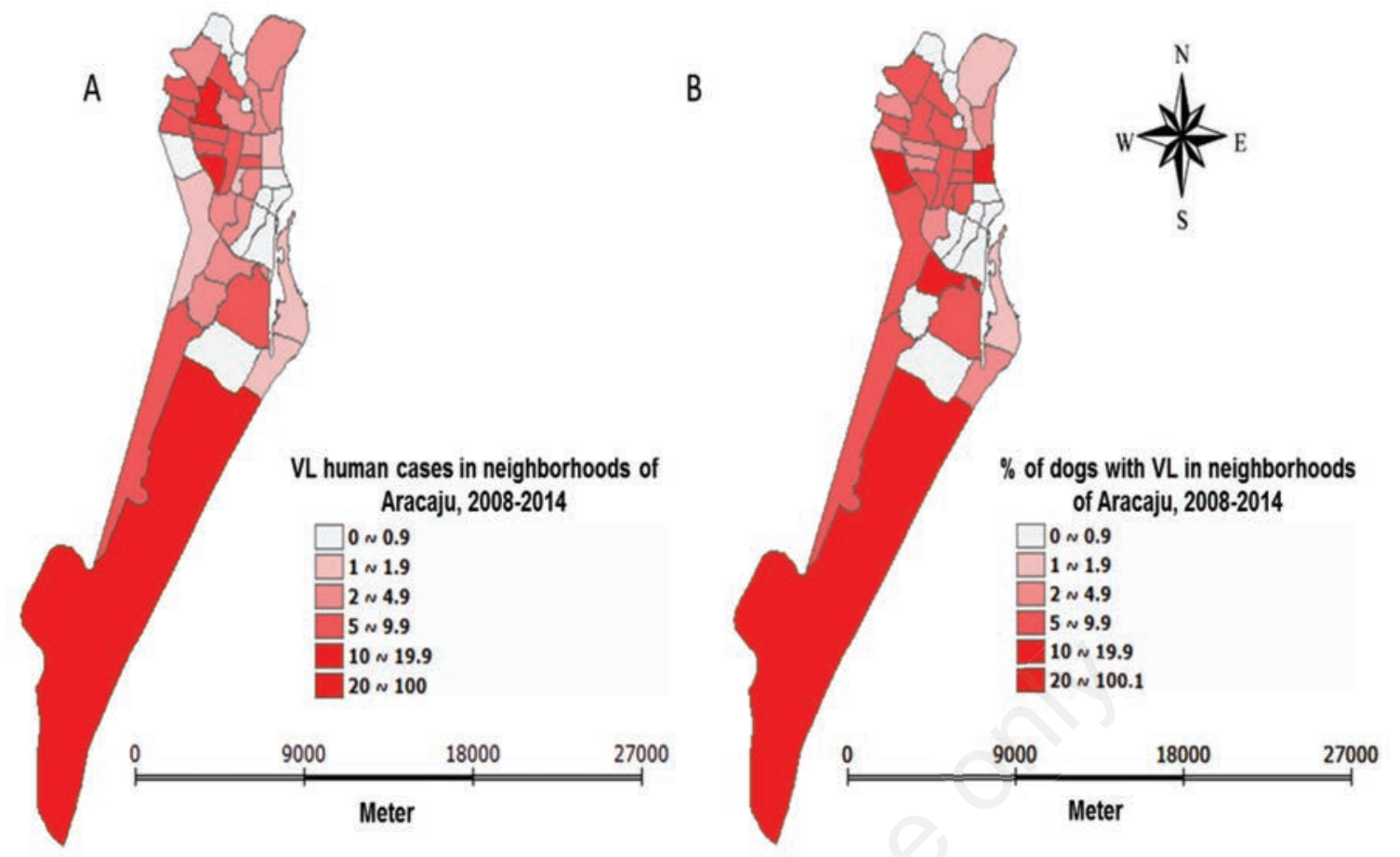

Figure 6. Frequency distribution map of human visceral leishmaniasis cases (A) and of dogs with visceral leishmaniasis (B) in the districts of Aracaju. The data represent the accumulative numbers of dogs and human visceral leishmaniasis cases from 2008 to 2014.
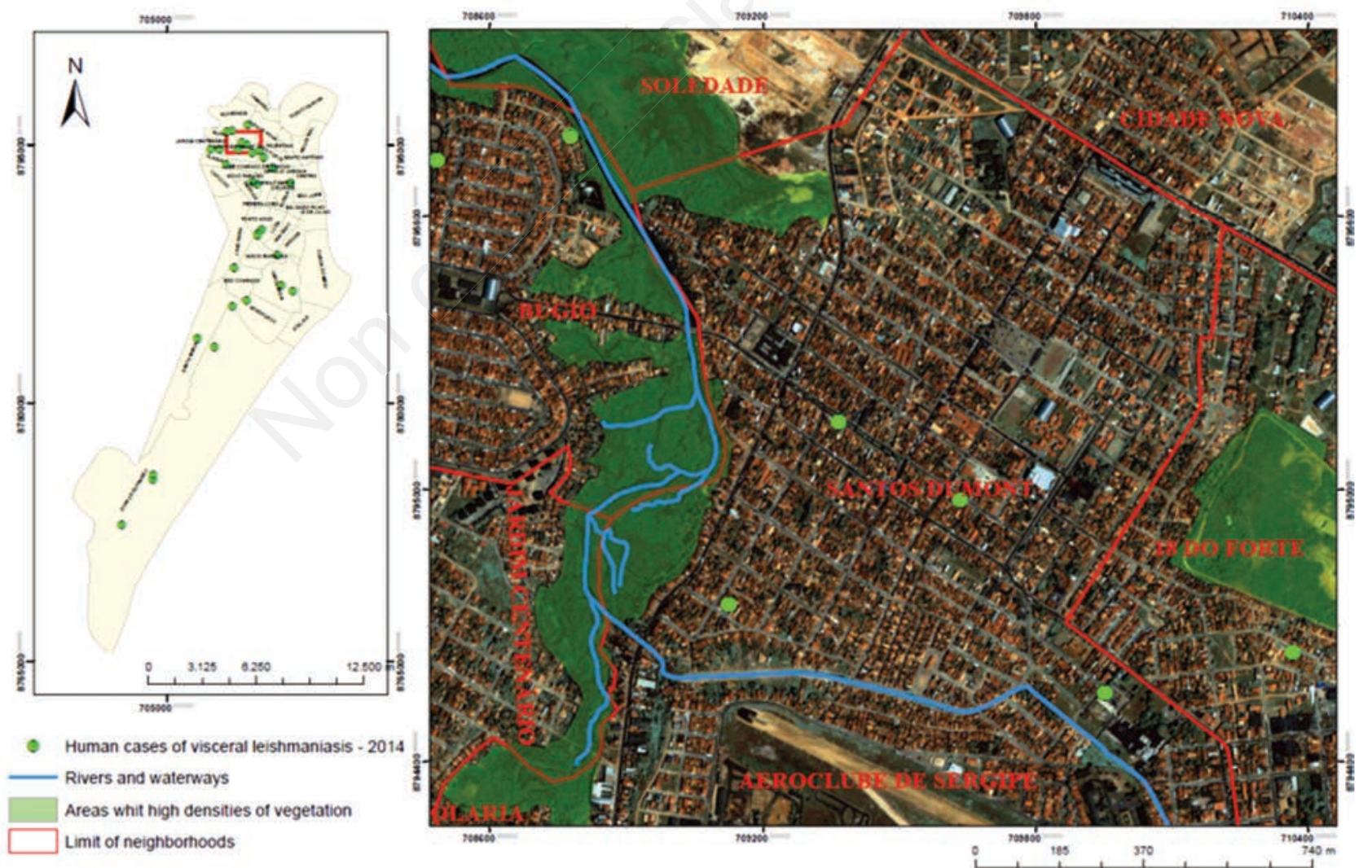

Figure 7. Areas of the highest prevalence of human cases of visceral leishmaniasis in Aracaju, Brazil, in 2014. The environmental peculiarities considered as risk factors for visceral leishmaniasis were mapped, such as areas of deforestation, water sources and home backyards with vegetation. 


\section{Discussion}

Our study using time series revealed that human cases of VL and dogs positive for VL have increased from 2008 to 2014; in 2010 the human cases increased considerably. It is also clear that the incidence in Aracaju city is higher than the incidence of the State of Sergipe. This data points to an urbanisation phenomenon. Taken together, the work proposes that urban growth of Aracaju, especially in periurban areas of recent expansion, fosters humans and domesticated dogs to enter into the natural environment of the sandfly, thereby leading to increased exposure and transmission of propagating Leishmania infections.

The dynamics of transmission of Leishmaniasis is seasonal and depends on the distribution of sand flies (Alvarenga et al., 2010). Climatic factors such as temperature, humidity and rainfall, also influences the sand flies population variance (Bhunia et al., 2010; Fischer et al., 2010). The large adaptability of L. longipalpis in urban environments, both inside and outside the home, and at different temperatures has influenced the dynamics of transmission of VL (Oliveira et al., 2008, 2013). This may be related to the urban growth of Aracaju, especially in periurban areas of recent expansion, which makes the man and domestic dogs entering in the natural environment of the sand fly and increase the risk of Leishmania infection (Góes et al., 2012; Gramiccia, 2011). Furthermore, the environment plays an important role in the VL transmission cycle. Poverty, associated with the rapid and disorganised expansion of periurban areas of large cities, leads to the formation of unsanitary home conditions, lack of housing infrastructure and sanitation from newly settled families in the periurban areas of big cities, favouring the spread of the disease (Almeida et al., 2011; Werneck, 2014).

For control of vector-borne diseases in Brazil, it is important to consider the urbanisation of the population and the change of the transmission behaviour of the disease from rural to urban or periurban (Harhay et al., 2011). Additionally, the same socioeconomic condition that favours the dissemination of VL, are also risk factors for other vector-born diseases, such as Dengue, Zika and Chikungunya. As a model, for example, this increase in dogs with VL may be associated with prohibition of euthanasia of infected dogs by the Center for Zoonosis Control of Aracaju, in 2013. The presence of infected dogs maintain the Leishmania transmission among species, increasing the incidence of VL in dogs and humans (Amóra et al., 2006; Felipe et al., 2014; Lara-Silva et al., 2015).

The analysis of the spatial distribution of cases of canine and human VL total cases in the districts of Aracaju indicate that there is a transmission to both mammals in the same areas. This data combined with the progressive increasing in the frequency of disease in both mammals, after 2010, should alert the authorities. Nevertheless, it is worth mentioning that the active search of infected dogs is directly related to areas with high incidences of human cases. However, it is likely that there are areas with infected dogs in areas without a prevalence of infected humans.

Geoprocessing has proven to be a very useful method to define areas at risk, enabling efficient monitoring and prevention strategies (Almeida et al., 2011; Tsegaw et al., 2013). Our use of geoprocessing techniques point to the existence of three regions as the main areas of disease transmission in the municipality: Expansion Zone, the North Zone peripheral areas, and the city centre. These regions have environmental quirks (deforestation, high humidity and vacant land with debris accumulation) and unfavourable socioeconomic conditions that justify greater transmission of dis- ease in these neighbourhoods. The spatial analysis of cases of VL in Aracaju has shown a worrying scenario regarding the distribution, transmission and maintenance of the disease in the region. However, the knowledge gained from these studies can be used to focus combined interventions strategies to the most affected areas by government officials, which can ensure cost-effectiveness of control measures to combat leishmaniasis.

\section{Conclusions}

The prevalence of canine infection by Leishmania sp. doubled in the municipality of Aracaju, between the years 2008 and 2014. In these years there was an increase in cases of human VL. An association of disease with male sex was observed, not seen in 0 14-year-old patients, suggesting either hormonal influence or higher exposure to the flebotomine by males from 15 to 49 years.

The spatial distribution analysis identifies areas of highest concentration of human and canine VL cases. The neighbourhoods located on the outskirts of town or in expansion areas showed the highest prevalence of the disease. These areas have known environmental risk factors for vector-borne transmissible diseases. Our results of an exponential increase in VL-positive dogs and superposition of dogs and human cases in the same areas suggest that the disease is expanding in urban areas, with the transmission of dogs to humans via the sand fly vector.

Understanding the dynamics of transmission of this disease, as well as the identification of risk areas for infection is essential to direct actions of epidemiological surveillance programmes of the municipality.

\section{References}

Alvarenga DG de, Maria P, Escalda F, Sylvio A, Tereza M, Duenhas F, 2010. Visceral leishmaniasis: retrospective study on factors associated with lethality. Rev Soc Bras Med Trop 43:194-7.

Almeida AS de, Medronho RDA, Werneck GL, 2011. Identification of risk areas for visceral leishmaniasis in Teresina, Piaui State, Brazil. Am J Trop Med Hyg 84:681-7.

Amóra SSA, Santos MJP, Alves ND, Costa SCG, Calabrese K da S, Monteiro AJ, Rocha MFG, 2006. Fatores relacionados com a positividade de cães para leishmaniose visceral em área endêmica do Estado do Rio Grande do Norte, Brasil. Ciência Rural 36:1854-9.

Belo VS, Struchiner CJ, Werneck GL, Barbosa DS, de Oliveira RB, Neto RGT, da Silva ES, 2013. A systematic review and meta-analysis of the factors associated with Leishmania infantum infection in dogs in Brazil. Vet Parasitol 195:1-13.

Bhunia GS, Kesari S, Jeyaram A, Kumar V, Das P, 2010. Influence of topography on the endemicity of Kala-azar: A study based on remote sensing and geographical information system. Geospat Health 4:155-65.

Dantas-Torres F, Solano-Gallego L, Baneth G, Ribeiro VM, de Paiva-Cavalcanti M, Otranto D, 2012. Canine leishmaniosis in the old and new worlds: unveiled similarities and differences. Trends Parasitol 28:531-8.

Dantas-Torres F, Tarallo VD, Latrofa MS, Falchi A, Lia RP, Otranto D, 2014. Ecology of phlebotomine sand flies and 
Leishmania infantum infection in a rural area of southern Italy. Acta Trop 137:67-73.

Faye B, Bucheton B, Bañuls AL, Senghor MW, Niang AA, Diedhiou S, Konaté O, Dione MM, Hide M, Mellul S, Knecht R, Delaunay P, Marty P, Gaye O, 2011. Seroprevalence of Leishmania infantum in a rural area of Senegal: analysis of risk factors involved in transmission to humans. T Roy Soc Trop Med Hyg 105:333-40.

Felipe K, Costa DL, Santos S, Amóra A, Fernandes C, Couto DA, Freitas S, Silva LF, Ney L, Laíse M, Sousa R De, 2014. Awareness of visceral leishmaniasis and its relationship to canine infection in riverside endemic areas in Northeastern Brazil. Rev Soc Bras Med Trop 47:607-12.

Fischer D, Thomas SM, Beierkuhnlein C, 2010. Temperaturederived potential for the establishment of phlebotomine sandflies and visceral leishmaniasis in Germany. Geospat Health 5:59-69.

Góes MAO, Melo CM de, Jeraldo V de LS, 2012. Time series of visceral leishmaniasis in Aracaju, state of Sergipe, Brazil (1999 to 2008): human and canine aspects. Rev Bras Epidemiol 15:298-307.

Gouvêa MV, Werneck GL, Costa CHN, de Amorim Carvalho FA, 2007. Factors associated to Montenegro skin test positivity in Teresina, Brazil. Acta Trop 104:99-107.

Gramiccia M, 2011. Recent advances in leishmaniosis in pet animals: Epidemiology, diagnostics and anti-vectorial prophylaxis. Vet Parasitol 181:23-30.

Harhay MO, Olliaro PL, Costa DL, Costa CHN, 2011. Urban parasitology visceral leishmaniasis in Brazil. Trends Parasitol 27:403-9.

IBGE, 2015. Instituto Brasileiro de Geografia e Estatistica, Aracaju, Sergipe, Brazil. Available from: http:/www.cidades. ibge.gov.br/xtras/perfil.php?lang=\& codmun=280030

Lara-Silva FDO, Michalsky ÉM, Fortes-Dias CL, Fiuza VDOP, Pessanha JEM, Regina-Silva S, de Avelar DM, Silva MA, da Costa AJA, Machado-Coelho GLL, Dias ES, 2015. Epidemiological aspects of vector, parasite, and domestic reservoir in areas of recent transmission and no reported human cases of visceral leishmaniasis in Brazil. Acta Trop 148:128-36.

Lopes EGP, Magalhães DF, Silva J, Haddad JP, Moreira EC, 2010. Distribuição temporal e espacial da leishmaniose visceral em humanos e cães em Belo Horizonte-MG, 1993 a 2007. Arq Bras Med Vet Zootec 62:1062-71.

Oliveira AG de, Marassa AM, Consales CA, Dorval ME, Fernandes CE, de Oliveira GR, Brazil RP, Galati EA, 2008. Observations on the feeding habits of Lutzomyia longipalpis (Lutz \& Neiva, 1912) (Diptera: Psychodidae: Phlebotominae) in Campo Grande, an endemic area of visceral leishmaniasis in Mato Grosso do Sul, Brazil. Acta Trop 107:238-41.

Oliveira EF, Silva EA, Casaril AE, Fernandes CE, Paranhos Filho AC, Gamarra RM, Ribeiro AA, Brazil RP, Oliveira AG, 2013. Behavioral aspects of Lutzomyia longipalpis (Diptera: Psychodidae) in urban area endemic for visceral leishmaniasis. J Med Entomol 50:277-84.

Quinnell RJ, Kennedy LJ, Barnes A, Courtenay O, Dye C, Garcez LM, Shaw MA, Carter SD, Thomson W, Ollier WE, 2003. Susceptibility to visceral leishmaniasis in the domestic dog is associated with MHC class II polymorphism. Immunogenetics 55:23-8.

Ribeiro VM, da Silva SM, Menz I, Tabanez P, Nogueira Fdos S, Werkhauser M, da Fonseca AL, Dantas-Torres F, 2013. Control of visceral leishmaniasis in Brazil: recommendations from Brasileish. Parasite Vectors 6:8.

Silva AVM da, Paula AA de, Cabrera MAA, Carreira JCA, 2005. Leishmaniose em cães domésticos: aspectos epidemiológicos. Cad. Saude Publica 21:324-8.

Travi BL, Ferro C, Cadena H, Montoya-Lerma J, Adler GH, 2002. Canine visceral leishmaniasis: dog infectivity to sand flies from non-endemic areas. Res Vet Sci 72:83-6.

Tsegaw T, Gadisa E, Seid A, Abera A, Teshome A, Mulugeta A, Herrero M, Argaw D, Jorge A, Aseffa A, 2013. Identification of environmental parameters and risk mapping of visceral leishmaniasis in Ethiopia by using geographical information systems and a statistical approach. Geospat Health 7:299-308.

Werneck GL, 2014. Visceral leishmaniasis in Brazil: rationale and concerns related to reservoir control. Rev Saude Publica 48:851-6.

WHO, 2010. First WHO report on neglected tropical diseases 2010: working to overcome the global impact of neglected tropical diseases. World Health Organization, Geneva, Switzerland. Available from: http://whqlibdoc.who.int/publications/2010/9789241564090_eng.pdf 